EGU21-1258

https://doi.org/10.5194/egusphere-egu21-1258

EGU General Assembly 2021

(c) Author(s) 2021. This work is distributed under

the Creative Commons Attribution 4.0 License.

\title{
Modelling dynamics of land use and ecosystem services changes in the Luanhe River Basin in China
}

\author{
Jiren $\mathbf{X} \mathbf{u}^{1}$, Brian Barrett ${ }^{2}$, and Fabrice Renaud ${ }^{1}$ \\ ${ }^{1}$ School of Interdisciplinary Studies, University of Glasgow, Dumfries, UK \\ ${ }^{2}$ School of Geographical \& Earth Sciences, University of Glasgow, Glasgow, UK
}

Quantifying land use dynamics is central to evaluate changes in terrestrial and aquatic ecosystems. It also allows for understanding how ecosystem services (ES) and ecosystem disservices (EDS) are affected by human interventions in the landscape. Finally, it can lead to the development of improved future land use management strategies for the achievement of the Sustainable Development Goals (SDGs). The Luanhe River Basin (LRB) is the most afforested river basin in North China and provides multiple ecosystem services which are related to several SDGs (e.g. SDG 6: Clean Water and Sanitation, 7: Affordable and Clean Energy, and 13: Climate Action). In this study, four scenarios: Trend, Expansion, Sustainability, and Conservation were developed based on different socioeconomic development and environmental protection targets as well as local plans and policies. Local stakeholders were consulted to develop these scenarios and to explore land use dynamics of the LRB and major challenges that the river basin may face by 2030 . Land use change was modelled with CLUMondo and ES and EDS were characterised using capacity matrices. The ecosystem services potential index (ESPI) and ecosystem disservices potential index (EDSPI) was calculated, and ES and EDS hotspots and coldspots were identified. The study found that forests and water bodies provided the highest overall ES capacity, while the lowest scores were recorded for built-up and unused land areas. Built-up land and cropland provided the highest overall EDS capacity, while the lowest EDS scores were for water bodies. The forests and water bodies, which were widespread in the upper-middle reaches of the basin, were hotspots of provisioning services, regulating services, cultural services and ecological integrity, while the hotspots of EDS were concentrated in the built-up land areas and the croplands, which were mainly distributed in the downstream of the LRB. Modelling results indicated that the LRB was likely to experience agricultural (crop and livestock) intensification and urban growth under all four future scenarios. The cropland intensity and the urban growth rate were much higher under the historical trend (Trend) scenario compared to those with more planning interventions (Expansion, Sustainability, and Conservation scenarios). The most significant increase of livestock density in grassland was projected under the Expansion scenario. Unless the forest area and biodiversity conservation targets are implemented (Conservation scenarios), the forest areas are projected to decrease under three scenarios by 2030. The ESPI of all the ES declined from 1980 to 2018 and would continue to decline until 2030 without sustainable and conservation development strategies. Compared with the EDSPI in 1980, the EDSPI under all future scenarios in 2030 was projected to increase. This study calls for establishing and implementing sustainable 
environmental protection policies as well as cross-regional and trans-provincial eco-compensation schemes for minimising trade-offs in ES. The methodological framework and findings of this study can guide regional sustainable development and rational utilisation of land resources in the LRB and other comparable river basins, and will be valuable for policy and planning purposes to the pursuance of SDGs at the sub-national scale. 